\title{
Aeroallergens, Allergic Disease, and Climate Change: Impacts and Adaptation
}

\author{
Colleen E. Reid ${ }^{1}$ and Janet L. Gamble ${ }^{2}$ \\ ${ }^{1}$ Environmental Health Sciences Division, School of Public Health, University of California, Berkeley, 50 University Hall, Berkeley, CA 94720 \\ ${ }^{2}$ Global Change Research Program, National Center for Environmental Assessment, Office of Research and Development, U.S. Environmental Protection \\ Agency, 1200 Pennsylvania Avenue, NW (MC 8601P), Washington, DC 20460
}

\begin{abstract}
Recent research has shown that there are many effects of climate change on aeroallergens and thus allergic diseases in humans. Increased atmospheric carbon dioxide concentration acts as a fertilizer for plant growth. The fertilizing effects of carbon dioxide, as well as increased temperatures from climate change, increase pollen production and the allergen content of pollen grains. In addition, higher temperatures are changing the timing and duration of the pollen season. As regional climates change, plants can move into new areas and changes in atmospheric circulation can blow pollen- and spore-containing dust to new areas, thus introducing people to allergens to which they have not been exposed previously. Climate change also influences the concentrations of airborne pollutants, which alone, and in conjunction with aeroallergens, can exacerbate asthma or other respiratory illnesses. The few epidemiological analyses of meteorological factors, aeroallergens, and allergic diseases demonstrate the pathways through which climate can exert its influence on aeroallergens and allergic diseases. In addition to the need for more research, there is the imperative to take preventive and adaptive actions to address the onset and exacerbation of allergic diseases associated with climate variability and change.
\end{abstract}

Key words: allergens, greenhouse effect, asthma, rhinitis, allergic, seasonal, dermatitis, atopic, prevention and control

\section{INTRODUCTION}

Climate change, caused in part by increased atmospheric concentrations of carbon dioxide $\left(\mathrm{CO}_{2}\right)$ and other greenhouse gases, is likely to result in increases in temperature and humidity, changes in the amount, distribution, and intensity of precipitation events, and increases in the intensity and frequency of certain extreme weather events

Published online: November 12, 2009

Correspondence to: Janet L. Gamble, e-mail: gamble.janet@epa.gov
(Solomon et al., 2007). These meteorological changes as well as changes in atmospheric $\mathrm{CO}_{2}$ concentrations can impact the production, distribution, dispersion, and allergenic content of aeroallergens and the growth and distribution of organisms that produce them (i.e., weeds, grasses, trees, and fungus). Shifts in aeroallergen production and, subsequently, human exposures may result in changes in the prevalence and severity of symptoms in individuals with allergic diseases. Air pollutants can independently, and in conjunction with aeroallergens, cause and exacerbate allergic diseases. Many air pollutant concentrations, par- 


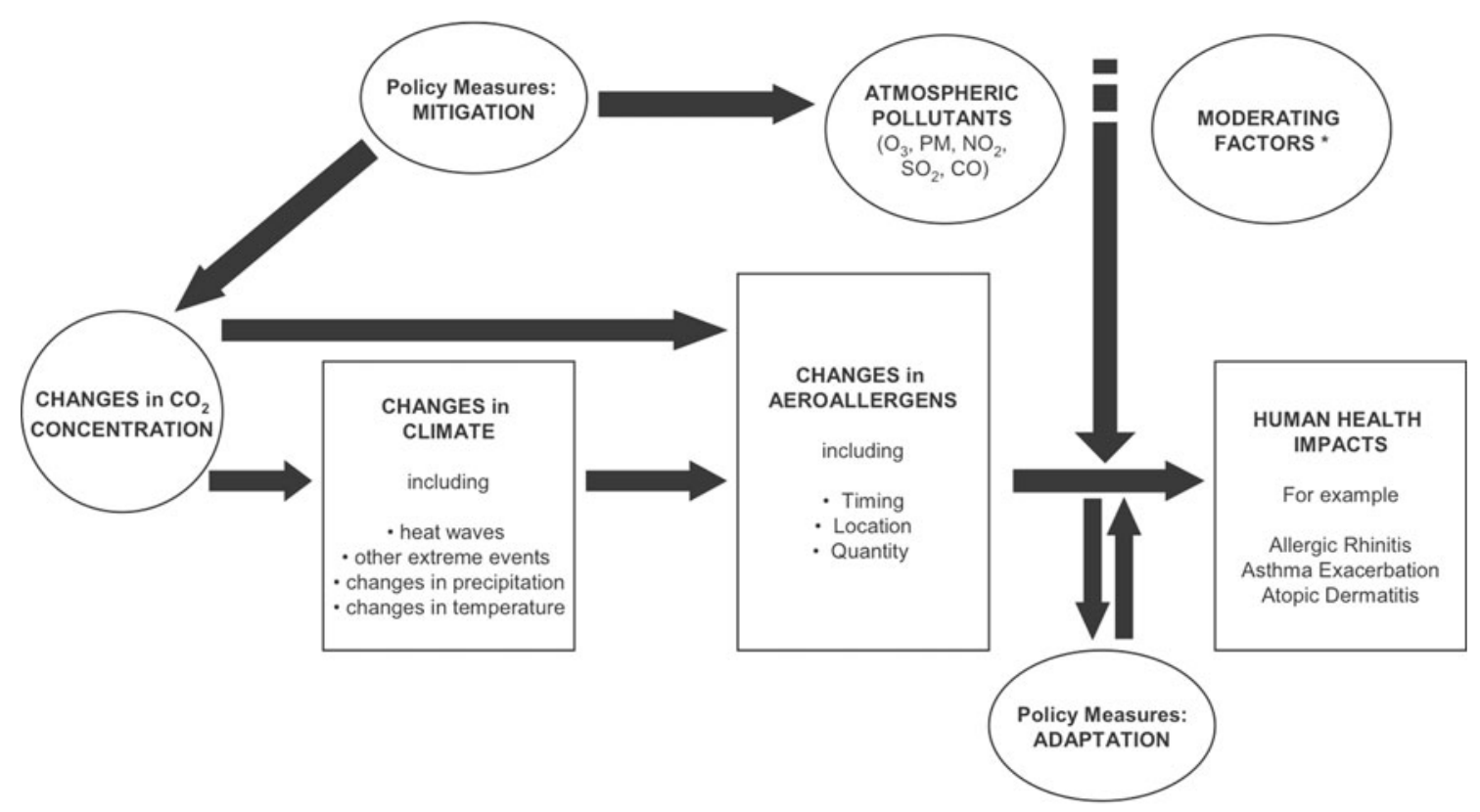

Modified from Bemard et al. 2001

* Moderating Factors are non-climate factors that may affect health outcomes, such as standards of living, health care access, and public health infrastructure

Figure 1. A framework of the impacts of climate change on aeroallergens and human health.

ticularly ozone, are affected by climatic changes. Figure 1 demonstrates these complex interactions.

Allergies and asthma collectively cost more than $\$ 30$ billion annually in the United States, both directly as costs to the health care system, and indirectly through lost productivity. A recent nationwide survey reported that $54.6 \%$ of people in the United States test positive for an allergic response to one or more allergens and more than 34 million Americans have been diagnosed with asthma (American Academy of Allergy Asthma and Immunology, 1996-2009). The three main allergic illnesses that have been associated with exposure to aeroallergens-allergic rhinitis (hay fever), asthma, and atopic dermatitis (eczema)individually and collectively impose both substantial health effects and large economic burdens. Although existing data suggest that aeroallergen levels have not been consistently increasing in all locations, the prevalence of asthma and allergic rhinitis has been increasing during the past few decades (Schoenwetter, 2000), a trend that seems to be mirrored in other countries (Asher et al., 2006). Estimates are that $15-20 \%$ of children worldwide have atopic dermatitis, and there is evidence to suggest that this figure may be increasing (O'Connell, 2004).

A variety of possible explanations for the increased prevalence of allergic diseases have been postulated. The increase in the prevalence of asthma has been attributed to higher levels of exposure to indoor allergens, especially cockroaches (Hamilton \& Eggleston, 1997; Hamilton, 2005; Phipatanakul, 2005). The hygiene hypothesis, which often is used to explain the increases in allergic diseases in developed countries, suggests that not being exposed to bacteria and infections at a young age can make one more likely to develop allergic diseases later in life (Sublett, 2005). This is exemplified by higher rates of hay fever in smaller families (Von Hertzen, 1998) and a protective effect for children who attend day care (Phipatanakul, 2005).

The rate at which the prevalence of respiratory allergies has been increasing argues against the trend being solely attributable to genetic factors. Given the failure of recent studies to consistently identify common determinants in lifestyle or home environment that could significantly affect disease development (Linneberg et al., 2000), the role of changes in aeroallergen concentrations related to climate change cannot be excluded, as has been hypothesized by Beggs and Bambrick (2005). Because the economic impacts of allergic diseases associated with aeroallergens and the quality-of-life impacts on those individuals who suffer from them are already substantial, any climate change-induced enhancement of this trend in the United States and elsewhere would be of particular concern. 
Some recent review articles have summarized the current understanding of the science on the impacts of climate change on aeroallergens (Beggs, 2004; Beggs \& Bambrick, 2005; D'Amato \& Cecchi, 2008; Shea et al., 2008) and on the interaction between aeroallergens and air pollution related to allergic diseases (Bartra et al., 2007; D'Amato \& Cecchi, 2008; Shea et al., 2008). A more recent review took the further step of outlining adaptation options focused on the role of medical professionals in preventing changes in these illnesses related to climate change (Shea et al., 2008). Our review goes one step further by analyzing the epidemiological literature that links allergic disease with changes in aeroallergens and climate. We also broaden our coverage of adaptation measures to include recommended actions for individuals and health care professionals, communities and organizations, as well as local, national, and international governments and agencies (Table 1).

\section{Climate Change and Aeroallergens}

\section{Aeroallergen Production}

Changes in meteorological factors can affect aeroallergen production, which, in turn, impacts the prevalence or severity of allergic illness via sensitivity and response pathways. For example, greater pollen concentrations in the air increase the chance of sensitization and subsequent exacerbation of illness. Exposures to higher concentrations of aeroallergens or allergen proteins may lead to more severe allergic responses (Nielsen et al., 2002; Singer et al., 2005). Whereas land-use change can have an impact on the amounts and types of pollen present at any location, climate also can play a role.

There are several examples where regional weather patterns, such as increased precipitation and temperature, have led to enhanced pollen production. Maximum pollen counts were higher during a warmer, wetter El Niño year than in the year before or after it in New England (Freye et al., 2001). Oak pollen counts in the San Francisco Bay Area have shown strong correlations with total rainfall from the previous year (Weber, 2003). However, increasing trends of total pollen production in cedar, oak, hickory, pecan, and birch in Oklahoma were not significantly correlated with increasing winter temperatures (Levetin, 2001), but the increasing pollen counts of cypress family pollen in Tulsa showed significant positive correlations with daily minimum, mean, and maximum temperatures and significant negative correlations with precipitation (Lo and Levetin, 2007).

A study in Denver, Colorado showed correlations between grass pollen counts and meteorological variables with 1-day time lags that were not consistent from year to year, suggesting that the intraseasonal meteorological conditions that determine pollen counts may vary from year to year or that preseason conditions are more important than day-today variations (Glassheim et al., 1995). An analysis of three cities in England found different trends in start date and total grass pollen count by city, signifying the need for regional assessments of climatic trends on pollen counts. Although meteorological factors explained some of the variation in grass pollen counts, changes in the amount of grassland in a region also played a large role (Emberlin et al., 1999).

Studies of ragweed in controlled environments and field studies show that pollen production can be expected to increase with increased temperature and $\mathrm{CO}_{2}$ levels. The Wan et al. (2002) experiment demonstrated that ragweed plants grown in warmer soil exhibited increases in number of stems, total biomass, percent coverage, pollen diameter, and total pollen production. Other experimental results have demonstrated that doubling $\mathrm{CO}_{2}$ levels from current to projected future levels would result in a $30-90 \%$ increase in ragweed pollen production (Ziska and Caulfield, 2000; Wayne et al., 2002; Rogers et al., 2006). Field studies of differences between rural and urban growth patterns also clearly showed that ragweed flowers earlier and produces greater amounts of pollen at urban locations where there are higher $\mathrm{CO}_{2}$ concentrations and temperatures compared with rural locations (Ziska et al., 2003).

Short-term forecasts indicate that although temperature and humidity can be strong predictors of mold concentrations, the effect varies by mold species and geography. A study in Denver, Colorado observed an upward trend in Cladosporium spore counts during 8 years that was significantly positively correlated with average temperature and humidity and significantly negatively correlated with precipitation; however, no significant trends were found for Alternaria or Epicoccum (Katial et al., 1997). Temperature and dew point were found to be important predictors of mold spore counts in Tulsa; however, meteorological factors alone could not predict all of the variability in spore counts (Troutt and Levetin, 2001). A study in New England observed higher mold counts after a warmer and wetter El Niño event (Freye et al., 2001). Overall, the relationship between climate 


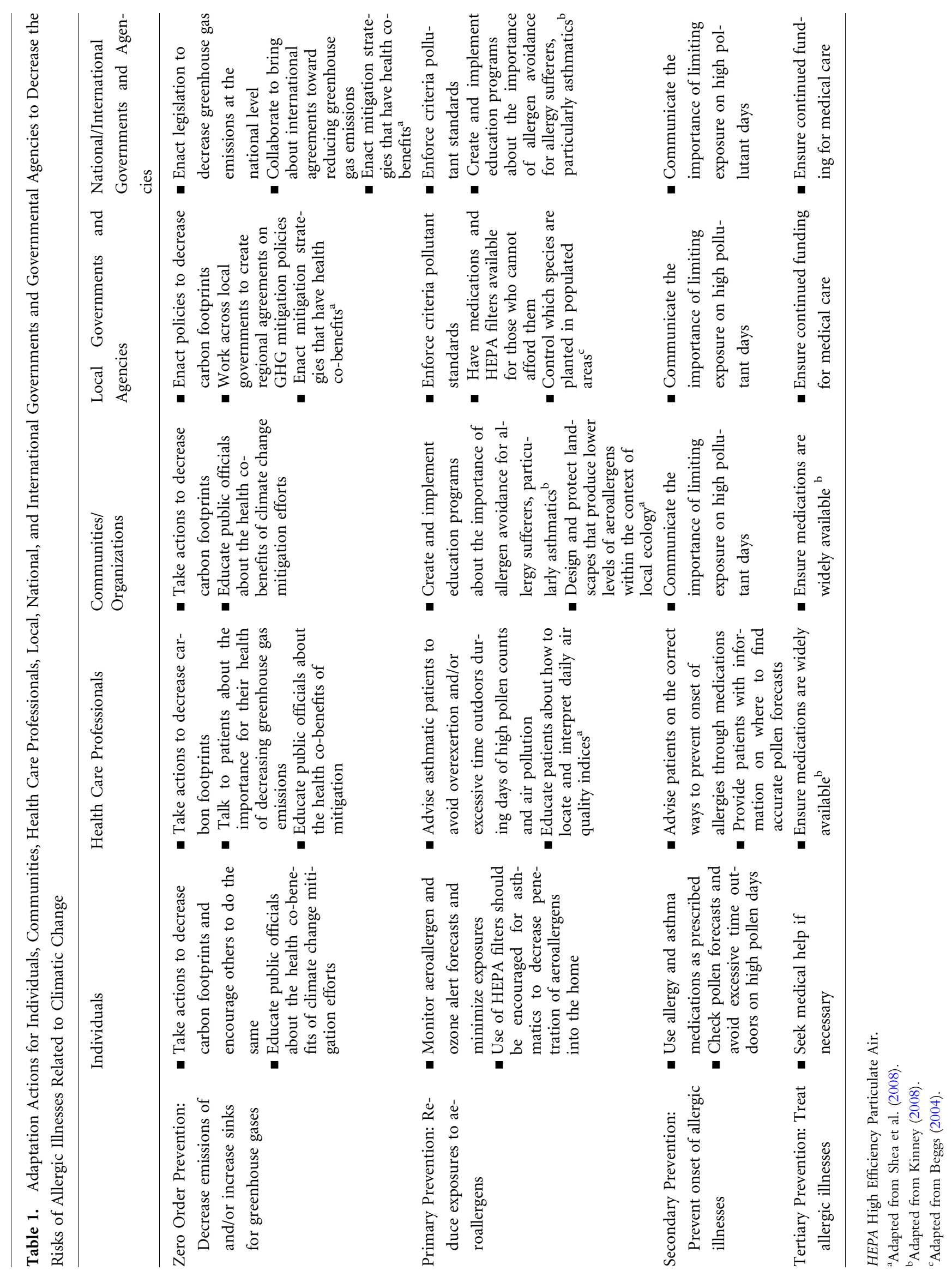


factors and mold species, extent, and geography suggests a complex multifactorial mechanism.

\section{Timing of Aeroallergen Production}

Changes in the timing and length of the pollen season lead to changes in human exposure, which can affect sensitization as well as exacerbation of allergic illnesses. Shifts in phenology are among the most consistent findings in studies of plant pollen production. A recent meta-analysis found that the current rate of spring phenological advance is 5 days per decade for numerous species of non-tree plants and 3 days earlier per decade for numerous species of trees (Root et al., 2003). Alterations in the timing of aeroallergen production in response to weather variables have been clearly demonstrated for certain tree species, but less so for grass and weed pollens and mold (Katial et al., 1997; Emberlin et al., 2002; Clot, 2003). Evidence is mixed for grass pollens, with trend studies showing substantial differences by region in England (Emberlin, 1994), earlier start dates in Switzerland (Clot, 2003), but no apparent effect after an El Niño event in New England (Freye et al., 2001).

Ragweed has been shown to flower earlier in urban environments where temperature and $\mathrm{CO}_{2}$ concentrations were higher compared with rural areas (Ziska et al., 2003). There is limited evidence of changes in the start dates for the emergence of mold, except for the El Niño event in New England, which indicated an earlier start (Freye et al., 2001). Some molds, such as Alternaria, are associated with agriculture and therefore the timing of production is associated with the harvest (Corden and Millington, 2001), which, if the timing of the harvest changes with climate change, could mean changes to the timing and duration of the mold season.

Studies in Spain have used the evidence of a linkage between temperatures and pollen season start to project future phenological changes based on output from climate models. These studies project that the Olea europaea L. pollen season in Andalusia will advance by 1 to 3 weeks by the end of the century (Galán et al., 2005) and that the Quercus pollen season may start a month earlier and have up to a $50 \%$ increase in pollen throughout Spain (GarciaMozo et al., 2006).

\section{Distribution and Dispersion of Aeroallergens}

Long-term responses to climate change (during 50100 years) are likely to involve range or distribution shifts in species and, in some cases, extinctions (Davis and Shaw, 2001; Joyce et al., 2001; Melillo et al., 2001). Ecological models indicate that the potential habitats for many tree species in the United States are likely to change, in some cases dramatically, by the end of the $21^{\text {st }}$ century. Potential habitats for trees favored by cool environments are likely to shift poleward and upward (Fischlin et al., 2007). The habitats of alpine, subalpine spruce/fir, and aspen communities will likely contract dramatically in the United States and largely shift into Canada. Potential habitats are likely to increase in the United States for oak/hickory, oak/pine, ponderosa pine, and arid woodland communities. Projections for vegetation redistribution suggest that savannahs and grasslands are likely to expand in the United States, especially in the Southeast, where hot and dry climate conditions are projected (Joyce et al., 2001). Climate change may act alone or in concert with other forces to influence dispersion or distribution of aeroallergens, which could result in significant impacts on allergic illnesses through exposure to novel or unusually high concentrations of aeroallergens.

Shifts in vegetation distribution are likely to occur during relatively long periods of time. Furthermore, the range of a species (e.g., birch) could contract or move northward and another (e.g., white oak) could take its place without any appreciable difference in allergic illness if those two species are cross-reactive. However, there is some indication that the introduction of new pollen into a region can lead to increased allergic illnesses in the population, even among people who did not have previous allergies to other pollens. The increase in pollen allergies to birch and ragweed pollens in the suburbs north of Milan has been attributed to the introduction of birch trees in the 1970s and 1980s and the natural spread of ragweed into the area in the 1980s. An investigation of people in Milan with new allergies solely to birch or ragweed pollen found that they had an older age of onset of allergies and were less likely to have a family history of allergic illnesses compared with people allergic to other pollens naturally found in the area (Asero, 2002). Although not directly related to changes in climate, this provides an example of how, if species ranges shift due to climate change, new cases of allergies in people who exhibit no previous symptoms could emerge.

There has been only limited research on how climate change could affect the dispersal of pollen and mold. Dispersion has the potential, via shifts in long-term weather patterns and extreme weather events, to expose and thus sensitize populations to novel allergens. There are cases of both pollen and dust being dispersed long distances from 
their release sites. For example, long distance dispersion of Juniperus ashei pollen in Tulsa, Oklahoma has been routinely observed and is associated with allergic illness in that community (Van de Water et al., 2003). Transcontinental transport of dust particulates also has been observed. During April 1998, the dust plume from two large dust storms over the Gobi desert crossed the Pacific Ocean and resulted in strong spikes in particulate matter concentrations 10 days later along the west coast of the United States (Husar et al., 2001). Although it is unclear whether there were health impacts of this dust event, other long-range transport events have transported pollen grains and fungal spores across long distances in desert dust (Shinn et al., 2003; Kellogg and Griffin, 2006). There also is evidence of pollen grains being transported long distances by wind without accompanying dust, for example, birch pollen from Poland and Germany to Denmark (Skjoth et al., 2007), and beech pollen from Italy and Germany to northeastern Spain (Belmonte et al., 2008).

\section{Allergenic Content of Aeroallergens}

Allergic symptoms are related to pollen in a dose-response manner (Singer et al., 2005). Whereas pollen concentration has been taken as the indicator of potential dose, the underlying mechanism for allergic symptoms comes in part from the protein allergens in the pollen (Ahlholm et al., 1998; Beggs, 1998; Singer et al., 2005). Recent research has examined the influence of meteorological variables, such as temperature and precipitation, and air pollutants, such as $\mathrm{CO}_{2}$, on the concentration of allergen protein, or the allergenicity, of pollen.

Singer et al. (2005) evaluated how Amb a 1 allergen (the main allergenic protein in ragweed pollen) concentrations changed in response to rising $\mathrm{CO}_{2}$ concentrations. Although total pollen protein remained unchanged, concentrations of $\mathrm{Amb}$ a 1 increased as a function of $\mathrm{CO}_{2}$ concentrations. After controlling for descendant group, another study found that IgE-immunoblotting responses were stronger in human sera exposed to pollen grown at higher temperatures (Ahlholm et al., 1998). The authors suggest soil temperature, which limits nutrient uptake and thus the rate of allergen synthesis, as a possible mechanism for the increased allergic response. Although research on allergen content of pollen/mold is limited, it does suggest that even if pollen production remained unchanged, allergic illness could increase because of increasing levels of allergenic protein due to higher $\mathrm{CO}_{2}$ concentrations.

\section{Climate Change and Allergic Diseases}

\section{Epidemiological Analyses of Meteorology, Aeroallergens, and Allergic Diseases}

There are very few examples of observational studies that investigate the linkages between weather, aeroallergens, and health outcomes. These studies provide limited evidence of the seemingly obvious, but difficult to demonstrate, link between weather, aeroallergen production, and subsequent illness.

Epton et al. (1997) conducted a 1-year prospective study to explore relationships between weather, fungal spore counts, pollen counts, and peak expiratory flow rates (PEFR) and asthma in a group of subjects with asthma. A small positive association was found between PEFR and mean temperature. The study also found an association between days with high basidiospore counts and nocturnal wakening and medication use to relieve asthma. The authors concluded that the effects of weather and aeroallergens on PEFR and asthma symptoms in the studied population were small and that other currently unknown causes may explain variations in asthma severity and exacerbations; however, these minimal effects also could be due to the high rate of anti-inflammatory medications being used by the cases and the lack of control subjects in this study.

Another prospective study of asthma admissions in Israel found that daily emergency room (ER) visits for asthma were positively correlated with $\mathrm{NO}_{\mathrm{x}}$ (nitrogen oxides), $\mathrm{SO}_{2}$ (sulfur dioxide), and high barometric pressure and negatively correlated with ozone $\left(\mathrm{O}_{3}\right)$, and minimum and maximum temperature. They found no correlation between asthma-related ER visits and pollen, spores, humidity, or particulates (Garty et al., 1998). However, a time-series study of the link between grass and weed pollen and emergency department (ED) visits for asthma in Montreal found significant correlations between increases in grass pollen concentrations and increases in first-time ED visits for asthma at lags of 3 days and 5 days, and that readmissions for asthma increased 4 days after an increase in grass pollen concentrations. Adding meteorological or air quality variables did not significantly alter the relationships observed between pollen and asthma (Héguy et al., 2008).

Whereas most epidemiological studies that investigate the relationship between meteorological variability and aeroallergens focus on asthma, there is some evidence of an 
impact of meteorological factors on the prevalence and intensity of atopic dermatitis and allergic rhinitis. Another Montreal study investigated the links between weather, Ambrosia (ragweed) pollen, and medical consultations for allergic rhinitis. Ambrosia pollen concentrations were significantly positively correlated with maximum, mean, and minimum temperatures but negatively correlated with precipitation. Logistic regression showed strong correlations between pollen count and higher medical consultations for allergic rhinitis on the day of and 1,2, 3, and 5 days after elevated pollen exposure (Breton et al., 2006). A cross-sectional population-based study of 6- to 7-yearolds in urban areas of three climatic regions in Spain found not only different rates of eczema in these regions, but also prevalence rates that were positively associated with precipitation and humidity and negatively associated with temperature and number of sunny hours (Suárez-Varela et al., 2008). This implies that as climate changes for a given region, rates of atopic dermatitis also could change; however, they did not specifically assess the role of allergen concentrations in this study. Further investigations of the relationship between meteorological factors, aeroallergens, and allergic diseases are needed to better understand whether the inconsistent findings of these studies are due to study design, location, population, or other factors.

\section{Extreme Weather Events and Aeroallergens}

Severe weather events, such as thunderstorms and hurricanes, provide intriguing evidence of an association between weather, aeroallergens, and allergic illness. There have been many documented cases of higher rates of asthma attacks during thunderstorms, not just for asthmatics but also for people who have previously only had allergic rhinitis. Thunderstorm winds and associated precipitation produce the correct conditions for pollen grains to burst and release allergen particles small enough to enter the lower airways (D'Amato et al., 2007). In England there were high correlations between the timing of thunderstorms, concentrations of Didymella, Cladosporium, and broken Alternaria spores, and asthma hospital admissions. This study also found that the odds of being sensitive to Alternaria and/or Cladosporium spores was significantly increased for the thunderstorm-induced asthma admissions compared with controls (Pulimood et al., 2007).

A 6-year time-series analysis of aeroallergens, air pollutants, and asthma admissions in a Birmingham, England children's hospital found that the fungal spore concentra- tion explained more of the increase in asthma rates on thunderstorm versus non-thunderstorm days than did pollens or air pollutants (Dales et al., 2003). Grundstein et al. (2008) found a significant correlation between asthma ED visits and thunderstorms in Atlanta, Georgia, and there was significant effect modification by rainfall and wind speed, in that there was only an effect in thunderstorms with rainfall and this effect increased with moderate and high wind speeds.

Hurricanes also have been shown to impact allergic diseases. The most widely studied of these is Hurricane Katrina, where large sections of New Orleans were flooded for weeks, resulting in extensive mold growth in buildings. Of 112 households in the New Orleans area assessed by the CDC, almost half the homes had "visible mold growth" and $17 \%$ had "heavy mold coverage," and allergy-causing molds were found both indoors and outdoors (Ratard et al., 2006). Solomon et al. (2006) also found high mold spore counts in October and November 2005 in New Orleans. Higher mold spore concentrations were found inside compared with outside and much higher spore concentrations were found in flooded areas compared with unflooded areas, which were higher than background concentrations.

Hospitals in New Orleans have reported an increased number of patients with allergy and cold symptoms, and doctors have suggested that allergy to the mold and dust circulating in New Orleans made residents susceptible to respiratory illness (Wilson, 2006). There have been reports of a nagging cough throughout New Orleans that has been nicknamed "Katrina cough" or "shelter cough," which may be partially due to the higher spore or other particulate concentration in the air (Manuel, 2006). Overall rates of asthma in children from the New Orleans area increased post-Katrina from $14 \%$ (2003) to $18 \%$ (2006) and was possibly higher for minority and underprivileged children or children residing in certain geographical areas that were affected by post-Katrina flooding (Epstein et al., 2005).

Current climate change projections show likely increases in heavy downpours and hurricane intensity but not necessarily frequency (Climate Change Science Program, 2008). Although an individual event like Hurricane Katrina cannot be attributed solely to climate change, and the post-Katrina mold could be attributed more to the response and not the storm itself, this example does highlight what could happen if more intense precipitation events occur without an increase in our ability to adapt or respond appropriately. 


\section{Climate Change, Air Pollution, Aeroallergens, and Allergic Diseases}

Some recent studies have shown that the interactions between air pollution, aeroallergens, and allergic diseases are complex and that air pollution may not only play a significant role in the etiology of some allergic diseases but that it also may modify the effect of aeroallergens on these diseases. D'Amato et al. (2002) hypothesize that the reason for the increase in urban allergic disease may be due to the role that air pollutants play in mediating the health effects of aeroallergens. The authors summarize the scientific literature that demonstrates these interactions: the inflammatory effects of $\mathrm{O}_{3}$, particulate matter $(\mathrm{PM})$, and $\mathrm{SO}_{2}$ allow for easier penetration of pollen allergens into the airways; air pollutants can increase the release of antigens in pollen grains that lead to allergic responses; and pollutants also can absorb pollen grains and thus prolong the retention of the pollen grains in the body once inhaled. Given that increases in temperature from climate change may increase ground-level ozone as well as aeroallergen concentrations, the interactions between these two airway irritants are important for further study.

Knowlton et al. (2007) placed the locations of ragweed pollen prevalence and areas with at least one ozone exceedance day per year on the same map because both of these exposures are associated with asthma. Notably, 14 of the 15 cities listed by the Asthma and Allergy Foundation of America as the "most challenging places to live with asthma" were in areas that had overlapping risks of ozone and ragweed. These regions of overlap highlight regions of vulnerability that may increase in size with climate change.

In observational studies of asthma, where aeroallergens and air pollutants could both be the cause, it is important to analyze the potential for confounding of one by the other. A few examples highlight the inconclusive results found in studies that investigate these confounding effects. It is important to note that these studies controlled for meteorological factors but did not specifically analyze the impacts of meteorological variability on the outcome. In a study that investigated the link between air pollution and ED visits for asthma in Alberta, Canada, adding aeroallergen data to the analysis did not alter risk estimates for air pollution on ED visits for asthma (Villeneuve et al., 2007). However, a study by Erbas et al. (2007), which focused on the relationship between grass pollen and ED visits for asthma in Melbourne, Australia, found that adding $\mathrm{NO}_{2}$ (nitrogen dioxide), but not $\mathrm{O}_{3}$ or $\mathrm{SO}_{2}$, made an impact on their model. They also found that the air particle index and $\mathrm{NO}_{2}$ were independently associated with asthma ED visits, and that grass pollen was still associated with asthma ED visits even when all air pollutants were added to the model (Erbas et al., 2007).

Two studies of ER visits for asthma in Madrid show the complexity of the roles of aeroallergens and air pollutants on asthma. Galán et al. (2003) reported that pollen did not modify the association between $\mathrm{O}_{3}, \mathrm{NO}_{2}$, and $\mathrm{PM}_{10}$ and asthma ER visits, but Tobías et al. (2004) found a relationship between three pollen types and asthma ER admissions that remained constant even when controlling for air pollutants. This study also found two epidemics of asthma that were correlated with peaks in pollen releases.

A study in Finland, however, found no relationship between asthma attacks and pollen or meteorological factors except for temperature, which had a low inverse correlation with asthma attacks, and air pollutants, specifically $\mathrm{NO}_{2}, \mathrm{SO}_{2}$, TSP (Total Suspended Particles) and $\mathrm{H}_{2} \mathrm{~S}$ (hydrogen sulfide), were significantly correlated with asthma attacks (Rossi et al., 1993). A time-series analysis of 7 years in ten cities in Canada found that controlling for air pollution and other allergens, such as mold spores and grass pollens, did not confound the relationship between tree pollen and asthma hospitalizations (Dales et al., 2008).

The interrelationships between climate variability, air pollution, and aeroallergens are complex and the different findings in the literature may be due to the specific aspects of a given study, such as the species of pollen, air pollutants, geography, current climate, and sensitization of the population. A recent review of these issues by D'Amato and Cecchi (2008) explains this complexity and demonstrates how projected climatic changes could have both positive and negative effects on respiratory allergies because of the multiple ways in which climatic and other global changes, such as urbanization and increased energy use, may impact air pollutants, aeroallergens, and ultimately allergic illnesses.

\section{CONCLUSIONS}

\section{More Research}

Further progress must be made in documenting and understanding the roles of climatic variability and change on aeroallergens and allergic diseases. Most of the research to date on aeroallergens and climate has been done in Europe. Although these studies can provide insight to other locations, 
Table 2. Proposed Research Agenda for Aeroallergens, Allergic Illnesses, and Climate Change

Disease surveillance

Aeroallergen and ecosystem dynamics and monitoring

Integrated assessments

Improve methods for disease prevention and mitigation
- Improve morbidity and mortality surveillance for asthma, atopic eczema, and allergic rhinitis globally

- Establish levels of allergen exposure that constitute a risk for development of asthma, eczema, and rhinitis, especially as that risk varies across susceptible groups

- Improve methods of detecting aeroallergens in the environment and increase the number of monitoring sites collecting continuous data globally

- Integrate long-term data series on all aeroallergens to clearly document future changes in aeroallergen production and distribution, as well as allergenicity

- Relate the biology of aeroallergens at various time scales and at the scale of plant or community succession

- Determine how ecosystem habitats are altered by climate change and subsequently lead to changes in habitats of aeroallergen-producing plants

- Link health, climate, and ecology data by employing new integrated approaches, such as geographic information systems

- Ensure compatibility and consistency of data sets across time scales

- Integrate health and climate indicators, socioeconomic changes, and technological changes into assessment models

- Link the long-term data sets on aeroallergens and allergic diseases through the Environmental Public Health Tracking Network ${ }^{\mathrm{a}}$

- Conduct experimental and field studies as needed to examine how allergen content and distribution of aeroallergens may be altered in response to climate change

- Specifically study the combined effects of $\mathrm{CO}_{2}$ and temperature and interactions between these and other variables, such as water and nutrient availability, disturbance, and competition

- Consider within-species genetic variation in response to changing $\mathrm{CO}_{2}$ concentration, bioavailability, and temperature

- Assess how the impacts of urban warming or land use changes may interact with observed impacts of climate change

- Investigate the links between molds and allergic illnesses in relation to meteorological variables

- Enhance our understanding of the interactions between air pollution and aeroallergens in disease causation through toxicological and epidemiological methods

- Develop more effective, sustainable approaches for aeroallergen control

- Improve methods to project changes in aeroallergen ranges, distribution, and concentration due to climate change to enable local health departments to make plans to minimize risks to the population

- Enhance programs to decrease other risk factors for asthma to lessen the burden due to nonaeroallergen stressors

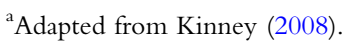

more research on this topic is needed in other regions of the world. A good first step would be the collection of integrated long-term data series on important aeroallergens. This can help document future changes in aeroallergen production and distribution, as well as facilitate epidemiological studies on the impacts of aeroallergens on allergic diseases, because the lack of data currently hinders such analyses.

Our review of the literature highlights the relatively few epidemiologic studies of allergic diseases and their rela- tionship to aeroallergens and climatic factors compared with what is known about climatic impacts on trees, grasses, fungi, and the aeroallergens that they produce. Coupled with the need for more general epidemiological studies that incorporate analyses of aeroallergens, allergic diseases, and meteorological factors, there is a clear need for epidemiological research on atopic eczema and allergic rhinitis. Additionally, better understanding of the interacting effects of aeroallergens and air pollutants on the 
development of allergic illnesses and the role that climate variability has on these is needed. For example, changes in the timing of pollen seasons could result in more overlap between the peak pollen period and the ozone season. Not only epidemiological but also chemical and toxicological analyses of the interactions between air pollutants and aeroallergens would improve understanding.

Although more research has been done on the impacts of climate change on aeroallergens themselves compared with allergic diseases, knowledge gaps remain. Further experimental and field studies are needed to examine how allergen content and distribution of aeroallergens may be altered in response to climate change. Research also could investigate other global environmental changes, particularly land-use changes in conjunction with climate change to better understand the interactions in these driving forces on aeroallergens and allergic diseases in the near-term and long-term. Table 2 outlines these and more areas for future research in this field.

\section{Prevention/Adaptation}

The evidence presented here demonstrates that climate change may alter the production, allergenicity, distribution, and timing of aeroallergens and thus increase the severity and prevalence of allergic diseases in humans. In addition, more intense hurricanes and thunderstorms could increase the frequency of epidemics of asthma even for those who are not diagnosed with asthma but who have allergic disorders. Given that the rates of allergic illnesses are likely increasing for reasons that we do not fully understand, preventive actions must be planned and implemented.

Preventive actions should include attempts to mitigate climate change by enhancing greenhouse gas sinks and decreasing greenhouse gas emissions that lead to global warming. Many climate change mitigation strategies have various health co-benefits, which can decrease air pollutants other than greenhouse gases, thus decreasing risks of respiratory and allergic diseases (e.g., Bloomberg and Aggarwala, 2008). However, even if greenhouse gas emissions are curtailed now, those that have already been emitted will influence the climate well into this century due to lags in the atmospheric system. Table 1 outlines various adaptive strategies, otherwise known as prevention strategies in the public health community (Ebi and Semenza, 2008), that can be implemented by various agencies to prevent increases in allergic diseases due to climate change.
With every adaptation/prevention option employed, attention needs to be given to the most vulnerable subpopulations. In regards to allergic illnesses, the most vulnerable are those with asthma, allergic rhinitis, or atopic eczema because they are already sensitized and thus are the most likely to experience exacerbations related to increased concentrations of aeroallergens. Additionally, the very young, the very old, the immunocompromised, and the medically uninsured bear the brunt of most health concerns related to climate change, including allergic diseases.

\section{ACKNOWLEDGEMENTS}

This article was developed partially under Cooperative Agreement No. X3-83085001 and X3-83388101 awarded by the U.S. Environmental Protection Agency to the Association of Schools of Public Health. However, the views expressed in this document are solely those of the authors and EPA does not endorse any products or commercial services mentioned in this publication.

\section{Open Access}

This article is distributed under the terms of the Creative Commons Attribution Noncommercial License which permits any noncommercial use, distribution, and reproduction in any medium, provided the original author(s) and source are credited.

\section{REFERENCES}

Ahlholm JU, Helander ML, Savolainen J (1998) Genetic and environmental factors affecting the allergenicity of birch (Betula pubescens ssp. czerepanovii [Orl.] Hämet-ahti) pollen. Clinical and Experimental Allergy 28(11):1384-1388

American Academy of Allergy Asthma \& Immunology (AAAAI) (1996-2009) Allergy and asthma statistics. http://www.aaaai. org/media/statistics/. Accessed 16 June 2009

Asero R (2002) Birch and ragweed pollinosis north of Milan: a model to investigate the effects of exposure to "new" airborne allergens. Allergy 57(11):1063-1066

Asher MI, Montefort S, Bjorksten G, Lai CKW, Strachan DP, Weiland SK, et al. (2006) Worldwide time trends in the prevalence of symptoms of asthma, allergic rhinoconjunctivitis, and eczema in childhood: ISAAC Phases One and Three repeat multicountry cross-sectional surveys. The Lancet 368:733-743

Bartra J, Mullol J, del Cuvillo A, Dávila I, Ferrer M, Jáuregui I, et al. (2007) Air pollution and allergens. Journal of Investigational Allergology and Clinical Immunology 17(Suppl 2):3-8 
Beggs PJ (1998) Pollen and pollen antigen as triggers of asthmawhat to measure? Atmospheric Environment 32(10):1777-1783

Beggs PJ (2004) Impacts of climate change on aeroallergens: past and future. Clinical and Experimental Allergy 34(10):1507-1513

Beggs PJ, Bambrick HJ (2005) Is the global rise of asthma an early impact of anthropogenic climate change? Environmental Health Perspectives 113(8):915-919

Belmonte J, Alarcón M, Avila A, Scialabba E, Pino D (2008) Longrange transport of beech (Fagus sylvatica L.) pollen to Catalonia (north-eastern Spain). International Journal of Biometeorology 52(7):675-687

Bernard SM, Samet JM, Grambsch A, Ebi KL, Romieu I (2001) The potential impacts of climate variability and change on air pollution-related health effects in the United States. Environmental Health Perspectives 109(Suppl 2):199-209

Bloomberg MR, Aggarwala RT (2008) Think locally, act globally: how curbing global warming emissions can improve local public health. American Journal of Preventive Medicine 35(5):414

Breton MC, Garneau M, Fortier I, Guay F, Louis J (2006) Relationship between climate, pollen concentrations of Ambrosia and medical consultations for allergic rhinitis in Montreal, 1994-2002. Science of the Total Environment 370(1):39-50

Climate Change Science Program (2008) Weather and climate extremes in a changing climate. Regions of focus: North America, Hawaii, Caribbean, and U.S. Pacific Islands. A report by the U.S. Climate Change Science Program and the Subcommittee on Global Change Research. Karl TR, Meehl GA, Miller CD, Hassol SJ, Waple AM, Murray WL (editors), Washington, DC: Department of Commerce, NOAA's National Climatic Data Center, $164 \mathrm{pp}$

Clot B (2003) Trends in airborne pollen: an overview of 21 years of data in Neuchâtel (Switzerland). Aerobiologia 19(3):227-234

Corden JM, Millington WM (2001) The long-term trends and seasonal variation of the aeroallergen Alternaria in Derby, UK. Aerobiologia 17(2):127-136

Dales RE, Cakmak S, Judek S, Coates F (2008) Tree pollen and hospitalization for asthma in urban Canada. International Archives of Allergy and Immunology 146(3):241-247

Dales RE, Cakmak S, Judek S, Dann T, Coates F, Brook JR, et al. (2003) The role of fungal spores in thunderstorm asthma. Chest 123(3):745-750

D'Amato G, Cecchi L (2008) Effects of climate change on environmental factors in respiratory allergic diseases. Clinical and Experimental Allergy 38(8):1264-1274

D'Amato G, Liccardi G, D'Amato M, Cazzola M (2002) Outdoor air pollution, climatic changes and allergic bronchial asthma. The European Respiratory Journal 20(3):763-776

D’Amato G, Liccardi G, Frenguelli G (2007) Thunderstormasthma and pollen allergy. Allergy 62(1):11-16

Davis MB, Shaw RG (2001) Range shifts and adaptive responses to quaternary climate change. Science 292:673-679

Ebi KL, Semenza JC (2008) Community-based adaptation to the health impacts of climate change. American Journal of Preventive Medicine 35(5):501-507

Emberlin J (1994) The effects of patterns in climate and pollen abundance on allergy. Allergy 49:15-20

Emberlin J, Detandt M, Gehrig R, Jaeger S, Nolard N, RantioLehtimäki A (2002) Responses in the start of Betula (birch) pollen seasons to recent changes in spring temperatures across Europe. International Journal of Biometeorology 46(4):159-170
Emberlin J, Mullins J, Corden J, Jones S, Millington W, Brooke M, et al. (1999) Regional variations in grass pollen seasons in the UK, long-term trends and forecast models. Clinical and Experimental Allergy 29(3):347-356

Epstein PR, Mills E, Frith K, Linden E, Thomas B, Weireter R (2005) Climate Change Futures: Health, Ecological and Economic Dimensions, Massachusetts: Center for Health and the Global Environment, pp 142

Epton MJ, Martin IR, Graham P, Healy PE, Smith H, Balasubramaniam R, et al. (1997) Climate and aeroallergen levels in asthma: a 12 month prospective study. Thorax 52(6):528-534

Erbas B, Chang J, Dharmage S, Ong EK, Hyndman R, Newbigin E, et al. (2007) Do levels of airborne grass pollen influence asthma hospital admissions? Clinical and Experimental Allergy 37(11):1641-1647

Fischlin A, Midgley GF, Price JT, Leemans R, Gopal B, Turley MDA, et al. (2007) Ecosystems, their properties, goods and services. In: Climate Change 2007: Impacts, Adaptation and Vulnerability. Contribution of Working Group II to the Fourth Assessment Report of the Intergovernmental Panel on Climate Change, Parry ML, Canziani OF, Palutikof JP, van der Linden PJ, Hanson CD (editors), Cambridge, United Kingdom: Cambridge University Press, pp 211-272

Freye HB, King J, Litwin CM (2001) Variations of pollen and mold concentrations in 1998 during the strong El Nino event of 1997-1998 and their impact on clinical exacerbations of allergic rhinitis, asthma, and sinusitis. Allergy and Asthma Proceedings 22:239-247

Galán C, García-Mozo H, Vázquez L, Ruiz L, de la Guardia CD, Trigo MM (2005) Heat requirement for the onset of the Olea europaea L. pollen season in several sites in Andalusia and the effect of the expected future climate change. International Journal of Biometeorology 49(3):184-188

Galán I, Tobias A, Banegas JR, Aranguez E (2003) Short-term effects of air pollution on daily asthma emergency room admissions. European Respiratory Journal 22(5):802-808

Garcia-Mozo H, Galán C, Jato V, Belmonte J, de la Guardia C, Fernandez D, et al. (2006) Quercus pollen season dynamics in the Iberian peninsula: response to meteorological parameters and possible consequences of climate change. Annals of Agricultural and Environmental Medicine 13(2):209-224

Garty BZ, Kosman E, Ganor E, Berger V, Garty L, Wietzen T, et al. (1998) Emergency room visits of asthmatic children, relation to air pollution, weather, and airborne allergens. Annals of Allergy, Asthma \& Immunology 81(6):563-570

Glassheim JW, Ledoux RA, Vaughan TR, Damiano MA, Goodman DL, Nelson HS, et al. (1995) Analysis of meteorologic variables and seasonal aeroallergen pollen counts in Denver, Colorado. Annals of Allergy, Asthma \& Immunology 75(2):149-156

Grundstein A, Sarnat SE, Klein M, Shepherd M, Naeher L, Mote T, et al. (2008) Thunderstorm associated asthma in Atlanta, Georgia. Thorax 63(7):659-660

Hamilton RG (2005) Assessment of indoor allergen exposure. Current Allergy and Asthma Reports 5(5):394-401

Hamilton RG, Eggleston PA (1997) Environmental allergen analyses. Methods 13(1):53-60

Héguy L, Garneau M, Goldberg MS, Raphoz M, Guay F, Valois M (2008) Associations between grass and weed pollen and emergency department visits for asthma among children in Montreal. Environmental Research 106(2):203-211. doi:S00139351(07)00223-X 
Husar RB, Tratt DM, Schichtel B, Falke SR, Li F, Jaffe D, et al. (2001) Asian dust events of April 1998. Journal of Geophysical Research 106(D16):18317-18330

Joyce L, Aber J, McNulty S, Dale V, Hansen A, Irland L, et al. (2001) Potential consequences of climate variability and change for the forests of the United States. In: Climate Change Impacts on the United States, National Assessment Synthesis Team, Cambridge, UK: Cambridge University Press, pp 489-524

Katial RK, Zhang Y, Jones RH, Dyer PD (1997) Atmospheric mold spore counts in relation to meteorological parameters. International Journal of Biometeorology 41(1):17-22

Kellogg CA, Griffin DW (2006) Aerobiology and the global transport of desert dust. Trends in Ecology \& Evolution 21(11):638-644

Kinney PL (2008) Climate change, air quality, and human health. American Journal of Preventive Medicine 35(5):459-467

Knowlton K, Rotkin-Ellman M, Solomon G (2007) Sneezing and wheezing: how global warming could increase ragweed allergies, air pollution, and asthma. Natural Resources Defense Council. http://www.nrdc.org/globalWarming/sneezing/sneezing.pdf. Accessed 21 April 2008

Levetin E (2001) Effects of climate change on airborne pollen. The Journal of Allergy and Clinical Immunology 107(2):S172

Linneberg A, Nielsen NH, Madsen F, Forlund L, Dirksen A, Jorgensen $T$ (2000) Increasing prevalence of specific IgE to aeroallergens in an adult population: two cross-sectional surveys 8 years apart. The Journal of Allergy and Clinical Immunology 106(2):247-252

Lo E, Levetin E (2007) Influence of meteorological conditions on early spring pollen in the Tulsa atmosphere from 1987-2006. The Journal of Allergy and Clinical Immunology 119(1S):101

Manuel J (2006) In Katrina's wake. Environmental Health Perspectives 114(1):A32-A39

Melillo J, Janetos A, Schimel D, Kittel T (2001) Vegetation and biogeochemical scenarios. In: Climate Change Impacts on the United States: The Potential Consequences of Climate Variability and Change. Report for the United States Global Change Research Program, Melillo JM, Janetos AC, Karl TR (editors), Cambridge, UK: Cambridge University Press, pp 73-91

Nielsen GD, Hansen JS, Lund RM, Bergqvist M, Larsen ST, Clausen SK, et al. (2002) IgE-mediated asthma and rhinitis I: a role of allergen exposure? Pharmacology \& Toxicology 90(5):231-242

O'Connell EJ (2004) The burden of atopy and asthma in children. Allergy 59(Suppl 78):7-11

Phipatanakul W (2005) Allergic rhinoconjunctivitis: epidemiology. Immunology and Allergy Clinics of North America 25(2):263-281

Pulimood TB, Corden JM, Bryden C, Sharples L, Nasser SM (2007) Epidemic asthma and the role of the fungal mold Alternaria alternata. The Journal of Allergy and Clinical Immunology 120(3):610-617. doi:S0091-6749(07)00970-0

Ratard R, Brown CM, Ferdinands J, Callahan D (2006) Health concerns associated with mold in water-damaged homes after Hurricanes Katrina and Rita-New Orleans, Louisiana, October 2005. Morbidity \& Mortality Weekly Report 55:41-44

Rogers CA, Wayne PM, Macklin EA, Muilenberg ML, Wagner CJ, Epstein PR, et al. (2006) Interaction of the onset of spring and elevated atmospheric $\mathrm{CO}_{2}$ on ragweed (Ambrosia artemisiifolia L.) pollen production. Environmental Health Perspectives 114(6):865-869
Root TL, Price JT, Hall KR, Schneider SH, Rosenzweig C, Pounds JA (2003) Fingerprints of global warming on wild animals and plants. Nature 421(6918):57-60

Rossi OV, Kinnula VL, Tienari J, Huhti E (1993) Association of severe asthma attacks with weather, pollen, and air pollutants. Thorax 48(3):244-248

Schoenwetter WF (2000) Allergic rhinitis: epidemiology and natural history. Allergy and Asthma Proceedings 21:1-6

Shea KM, Truckner RT, Weber RW, Peden DB (2008) Climate change and allergic disease. The Journal of Allergy and Clinical Immunology 122(3):443-453 quiz 454-455. doi:S0091-6749(08) 01181-0

Shinn EA, Griffin DW, Seba DB (2003) Atmospheric transport of mold spores in clouds of desert dust. Archives of Environmental Health 58(8):498-504

Singer BD, Ziska LH, Frenz DA, Gebhard DE, Straka JG (2005) Increasing Amb a 1 content in common ragweed (Ambrosia artemisiifolia) pollen as a function of rising atmospheric $\mathrm{CO}_{2}$ concentration. Functional Plant Biology 32(7):667-670

Skjoth CA, Sommer J, Stach A, Smith M, Brandt J (2007) The long-range transport of birch (Betula) pollen from Poland and Germany causes significant pre-season concentrations in Denmark. Clinical \& Experimental Allergy 37(8):1204-1212

Solomon GM, Hjelmroos-Koski M, Rotkin-Ellman M, Hammond SK (2006) Airborne mold and endotoxin concentrations in New Orleans, Louisiana, after flooding, October through November 2005. Environmental Health Perspectives 114(9):1381-1386

Solomon S, Qin D, Manning M, Alley RB, Berntsen T, Bindoff NL, et al. (2007) Technical summary. In: Climate Change 2007: The Physical Science Basis, Contribution of Working Group I to the Fourth Assessment Report of the Intergovernmental Panel on Climate Change, Solomon S, Quin D, Manning M, Chen Z, Marquis M, Averyt KB, Tignor M, Miller HL (editors), Cambridge, United Kingdom: Cambridge University Press

Suárez-Varela MM, García-Marcos Alvarez L, Kogan MD, González AL, Gimeno AM, Ontoso IA, et al. (2008) Climate and prevalence of atopic eczema in 6- to 7-year-old school children in Spain. ISAAC PhASE III. International Journal of Biometeorology 52(8):833-840. doi:10.1007/s00484-008-0177-0

Sublett JL (2005) The environment and risk factors for atopy. Current Allergy and Asthma Reports 5:445-450

Tobías A, Galán I, Banegas JR (2004) Non-linear short-term effects of airborne pollen levels with allergenic capacity on asthma emergency room admissions in Madrid, Spain. Clinical \& Experimental Allergy 34(6):871-878

Troutt C, Levetin E (2001) Correlation of spring spore concentrations and meteorological conditions in Tulsa, Oklahoma. International Journal of Biometeorology 45(2):64-74

Van de Water PK, Keever T, Main CE, Levetin E (2003) An assessment of predictive forecasting of Juniperus ashei pollen movement in the Southern Great Plains, USA. International Journal of Biometeorology 48(2):74-82

Villeneuve PJ, Chen L, Rowe BH, Coates F (2007) Outdoor air pollution and emergency department visits for asthma among children and adults: a case-crossover study in northern Alberta, Canada. Environmental Health 6:40. doi:10.1186/1476-069X-6-40

Von Hertzen L (1998) The hygiene hypothesis in the development of atopy and asthma-still a matter of controversy? Quarterly Journal of Medicine 91(11):767-771

Wan S, Yuan T, Bowdish S, Wallace L, Russell SD, Luo Y (2002) Response of an allergenic species, Ambrosia psilostachya 
(Asteraceae), to experimental warming and clipping: implications for public health. American Journal of Botany 89(11):18431846

Wayne P, Foster S, Connolly J, Bazzaz F, Epstein P (2002) Production of allergenic pollen by ragweed (Ambrosia artemisiifolia L.) is increased in $\mathrm{CO}_{2}$-enriched atmospheres. Annals of Allergy, Asthma \& Immunology 88(3):279-282

Weber RW (2003) Meteorologic variables in aerobiology. Immunology and Allergy Clinics of North America 23(3):411-422

Wilson JF (2006) Health and the environment after Hurricane Katrina. Annals of Internal Medicine 144(2):153-156
Ziska LH, Caulfield FA (2000) Rising $\mathrm{CO}_{2}$ and pollen production of common ragweed (Ambrosia artemisiifolia), a known allergyinducing species: implications for public health. Australian Journal of Plant Physiology 27(10):893-898

Ziska L, Gebhard D, Frenz DA, Faulkner S, Singer BD, Straka JG (2003) Cities as harbingers of climate change: common ragweed, urbanization, and public health. The Journal of Allergy and Clinical Immunology 111(2):290-295 